\title{
Synoviocytes, not chondrocytes, release free radicals after cycles of anoxia/re-oxygenation
}

\author{
Nicole Schneider ${ }^{\mathrm{a}, \mathrm{b}, \mathrm{c}, *}$, Ange L. Mouithys-Mickalad ${ }^{\mathrm{b}}$, Jean-Philippe Lejeune ${ }^{\mathrm{a}, \mathrm{c}}$, \\ Ginette P. Deby-Dupont ${ }^{\mathrm{b}, \mathrm{d}}$, Maryse Hoebeke ${ }^{\mathrm{b}, \mathrm{e}}$, Didier A. Serteyn ${ }^{\mathrm{a}, \mathrm{b}, \mathrm{c}}$ \\ a Department of Clinical Sciences, Large Animal Surgery, Faculty of Veterinary Medicine, University of Liège, B41, Sart Tilman, 4000 Liège, Belgium \\ ${ }^{\mathrm{b}}$ Centre of Oxygen Research and Development (CORD), Institute of Chemistry, University of Liège, B6a, Sart Tilman, 4000 Liège, Belgium \\ ${ }^{\mathrm{c}}$ Centre Européen du Cheval de Mont-le-Soie, 6698 Grand-Halleux, Belgium \\ ${ }^{\mathrm{d}}$ Department of Anesthesia and Intensive Care, University Hospital, B 35, University of Liège, B35, Sart Tilman, 4000 Liège, Belgium \\ ${ }^{\mathrm{e}}$ CORD, Laboratory of Experimental Imaging, Department of Physics, University of Liège, B5, Sart Tilman, 4000 Liège, Belgium
}

Received 21 June 2005

Available online 5 July 2005

\begin{abstract}
By oxymetry and electron paramagnetic resonance (EPR), we investigated the effects of repeated anoxia/re-oxygenation (A/R) periods on the respiration and production of free radicals by synoviocytes (rabbit HIG-82 cell line and primary equine synoviocytes) and equine articular chondrocytes. Three periods of $20 \mathrm{~min}$ anoxia followed by re-oxygenation were applied to $10^{7}$ cells; $\mathrm{O}_{2}$ consumption was measured before anoxia and after each re-oxygenation. After the last A/R, cellular free radical formation was investigated by EPR spectroscopy with spin trapping technique $\left(n=3\right.$ for each cell line). Both types of synoviocytes showed a high $\mathrm{O}_{2}$ consumption, which was slowered after anoxia. By EPR with the spin trap POBN, we proved a free radical formation. Results were similar for equine and rabbit synoviocytes. For chondrocytes, we observed a low $\mathrm{O}_{2}$ consumption, unchanged by anoxia, and no free radical production. These observations suggest an oxidant activity of synoviocytes, potentially important for the onset of osteoarthritis.
\end{abstract}

(C) 2005 Elsevier Inc. All rights reserved.

Keywords: Equine; Articular chondrocytes; Synoviocytes; Free radical; Electron spin resonance; Anoxia

Synovitis is commonly considered to be an initial change in joints of athletic horses and associated to repeated trauma. Ischemic conditions have been evoked as secondary consequence of joint effusion in the followup [1]. In 1989, it was pointed out that movements of an inflamed joint could lead to ischemia/reperfusion injury and might lead to the persistence of inflammatory joint disease by the local production of oxygen free radicals [2]. If acute or chronic trauma could already alter the blood supply of a sound synovial membrane, leading to cycles of ischemia/reperfusion (via edema and tran-

\footnotetext{
* Corresponding author.

E-mail address: ni.schneider@gmx.net (N. Schneider).
}

sient tissue hypoxia), this might start the production of reactive oxygen species (ROS) and could participate by intracellular and extracellular oxidative damage to progressive cartilage degradation and osteoarthritis. In a traumatic joint submitted to anoxia/re-oxygenation $(\mathrm{A} / \mathrm{R})$, both synoviocytes and chondrocytes could be theoretically responsible for ROS production. Articular chondrocytes in vivo live under poor oxygen $\left(\mathrm{O}_{2}\right)$ tension [3]. We already observed that equine articular chondrocytes in culture could survive for more than 10 days to near anoxia conditions $\left(<1 \% \mathrm{O}_{2}\right.$ in the surrounding atmosphere) [4], and we recently observed that the $\mathrm{O}_{2}$ uptake of equine articular chondrocytes was very low ( $20.5 \mathrm{pmol} \mathrm{O}_{2} / \mathrm{min} / 10^{6}$ cells), even if they were cultured 
at $21 \% \mathrm{O}_{2}$ during $48 \mathrm{~h}$ before the assays. Their respiratory rate did not increase after an anoxia period of 30 min (data submitted for publication).

The synoviocytes are the second kind of articular cells which we can suppose as implicated in ROS production, at least under stimulating conditions such as $\mathrm{A} / \mathrm{R}$ or acute inflammation. But, no data are available in literature about the ROS producing capacity of synoviocytes.

So we were interested to study the capacity of equine articular chondrocytes and synoviocytes to produce free radicals in $\mathrm{A} / \mathrm{R}$ conditions. To reach this goal, we used equine articular chondrocytes and synoviocytes (rabbit synoviocyte cell line HIG-82 and synoviocytes isolated from horse joint) and oxymetry coupled to electron spin resonance spectroscopy (EPR) in combination with the spin trapping technique. We previously designed an A/R model for chondrocytes (data submitted for publication, see above). A similar model was established for synoviocytes. With these chondrocyte and synoviocyte models, we tried to demonstrate whether synoviocytes or chondrocytes had different respiration rates and were able to produce free radicals when submitted to $A / R$ cycles.

\section{Materials and methods}

Reagents. PenStrep (penicillin $10^{4} \mathrm{IU} / \mathrm{ml}$, steptomycin $10 \mathrm{mg} / \mathrm{ml}$ ) and Hepes were from Cambrex (Verviers, Belgium). Collagenase (type IA, Clostridium histolyticum) and bovine testicular hyaluronidase type IV-S were from Sigma-Aldrich (Bornem, Belgium). Amphotericin B $(250 \mu \mathrm{g} / \mathrm{ml})$, gentamycin $(50 \mathrm{mg} / \mathrm{ml})$, proline, glutamine, DMEM (Dulbecco's modified Eagle's medium) with $1 \mathrm{~g} / \mathrm{L}$ glucose (without phenol red), Ham's F 12, trypsin/EDTA in HBSS, and foetal bovine serum (FBS) were purchased from Invitrogen (Merelbeke, Belgium). A working solution of special mix of antibiotics (antibiotic special mix: $2.5 \mu \mathrm{g} / \mathrm{ml}$ polymixin $\mathrm{B}, 5 \mu \mathrm{g} / \mathrm{ml}$ gentamycin, and $5 \mu \mathrm{g} / \mathrm{ml}$ vancomycin) was prepared either in DMEM or Ham's F 12 milieu. Ethanol (EtOH) and the spin trap agent, $\alpha$-(4-pyridyl 1-oxide)- $N$-tert-butylnitrone (POBN), were purchased from Aldrich (Belgium). Pronase (type E of Streptomyces griseus) and analytical grade sodium, potassium, calcium, and magnesium chlorides, magnesium sulphate, sodium hydrogen carbonate and hydrogen phosphate, potassium dihydrogen phosphate, and glucose were from Merck (VWR International, Leuven, Belgium). Trypan blue was from ICN Biomaterials (Eschwege, Germany). Gases were obtained from Air Liquide (Belgium). Spin trap was dissolved in Hanks' balanced salt solution added with glucose (HBSS-G: $138 \mathrm{mM}$ $\mathrm{NaCl}, 5.4 \mathrm{mM} \mathrm{KCl}, 4 \mathrm{mM} \mathrm{NaHCO}, 34 \mathrm{mM} \mathrm{Na} \mathrm{HPO}_{4}, 0.33 \mathrm{mM}$ $\mathrm{KH}_{2} \mathrm{PO}_{4}, 0.4 \mathrm{mM} \mathrm{MgSO} \cdot \cdot 7 \mathrm{H}_{2} \mathrm{O}, 0.5 \mathrm{mM} \mathrm{MgCl} 2 \cdot 6 \mathrm{H}_{2} \mathrm{O}, 1.4 \mathrm{mM} \mathrm{Ca}-$ $\mathrm{Cl}_{2} \cdot \mathrm{H}_{2} \mathrm{O}$, and $5.6 \mathrm{mM}$ glucose; $\mathrm{pH}$ 7.4).

Chondrocyte and synoviocyte isolation from equine joint. The articular chondrocytes and synoviocytes were harvested from the stifle joints of two trotting horses ( 4 and 5 years) euthanised for welfare reasons, but without orthopedic problems. An area of about $20 \times 20 \mathrm{~cm}$ at the stifle was clipped and the skin was removed without preliminary opening of the joint cavity. The joint capsule was aseptically opened and the synovial membrane was carefully dissected. The recovered pieces were cut to small pieces $\left(4 \mathrm{~mm}^{2}\right)$ and submitted to an enzymatic digestion $(3.5 \mathrm{~h})$ in around $20 \mathrm{ml}$ of the antibiotic special mix in Ham's F12 nutrient mixture enriched with 1\% PenStrep, $1 \%$ amphotericin B, and $0.75 \mathrm{mg} / \mathrm{ml}$ of type IA of Clostridium histolyticum.
The articular chondrocytes were isolated aseptically as previously described [4]. Briefly, the cartilage was cut in small pieces and submitted to a triple enzymatic digestion (sequentially: $1100 \mathrm{IU} / \mathrm{ml}$ hyaluronidase, $0.5 \mathrm{mg} / \mathrm{ml}$ pronase, and $1 \mathrm{mg} / \mathrm{ml}$ collagenase) in around $20 \mathrm{ml}$ of the antibiotic special mix in DMEM, added with $10 \mathrm{mM}$ Hepes, $10 \%$ heat-inactivated FBS, $2 \mathrm{mM}$ proline, $200 \mu \mathrm{g} / \mathrm{ml}$ glutamine, and $0.5 \mu \mathrm{g} / \mathrm{ml}$ amphotericin B.

After digestion, the synoviocyte and chondrocyte suspensions were filtered (cell strainer porosity $70 \mu \mathrm{m}$ ), centrifuged ( $5 \mathrm{~min}$ at $1000 \mathrm{rpm}$ ), and washed three times in their respective culture medium. The cells were counted and their viability was quantified by trypan blue exclusion $(0.4 \%$ in buffered saline solution) before further culture.

Culture conditions. The rabbit synoviocyte cell line (HIG-82; LGC Promochem SARL Molsheim France) and the equine synoviocytes were cultured in Ham's F12 medium supplemented with $10 \%$ heatinactivated FBS, $0.2 \%$ gentamycin, $1 \%$ PenStrep, and $1 \%$ amphotericin $\mathrm{B}$ at $37{ }^{\circ} \mathrm{C}$ under humidified atmosphere $\left(5 \% \mathrm{CO}_{2}\right.$ and $95 \%$ air). Prior to the assays, the monolayered synoviocytes were detached by incubation at $37^{\circ} \mathrm{C}$ with a trypsin/EDTA solution (4 min incubation for rabbit cells and $6 \mathrm{~min}$ for equine primary synoviocytes). The cells were distributed at $10^{7}$ per tube, centrifuged at $400 \mathrm{~g}$ for $5 \mathrm{~min}$, and the cell pellets were immediately used for oxymetry and EPR assays (see below).

The articular equine chondrocytes were distributed at $10^{7}$ cells per $20 \mathrm{ml}$ in Falcon tubes and cultured in DMEM containing 10\% heatinactivated FBS, $2 \mathrm{mM}$ proline, $200 \mu \mathrm{g} / \mathrm{ml}$ glutamine, $1 \%$ PenStrep, $10 \mathrm{mM}$ Hepes, and $1 \%$ amphotericin $\mathrm{B}$. The medium has been adjusted to $5 \% \mathrm{O}_{2}, 5 \% \mathrm{CO}_{2}$, and $90 \% \mathrm{~N}_{2}$ by bubbling during 30 min with a prepared gas mixture. The Falcon tubes were enclosed in an airtight container with an $\mathrm{O}_{2}$ gas phase tension of $5 \%$, in the presence of $5 \%$ $\mathrm{CO}_{2}$, and $90 \% \mathrm{~N}_{2}$ in a humidity-saturated atmosphere 2 days before the oxymetry onset. The samples were cultured at $37{ }^{\circ} \mathrm{C}$ on an orbital shaker $(70 \mathrm{rpm})$. Cell handling for the culture at $5 \% \mathrm{O}_{2}$ was performed in a sterile glove box (glove box C45201; Fisher Bioblock, Tournai, Belgium), gas-controlled $\left(\mathrm{N}_{2}, \mathrm{O}_{2}\right.$, and $\left.\mathrm{CO}_{2}\right)$ by micro flow rotameters. The $\mathrm{O}_{2}$ content of the glove box was monitored with an oxymeter (Oxycom $100 \mathrm{D}$, Germany). After this preconditioning culture period, the tubes were centrifuged at $400 \mathrm{~g}$ for $5 \mathrm{~min}$. The cell number was readjusted to $10^{7}$ per tube (with a viability determined by trypan blue exclusion superior to $95 \%$ ) and the cell pellets were recovered for the oxymetry and EPR assays.

Oxymetry and anoxialre-oxygenation. The $\mathrm{O}_{2}$ consumption by $10^{7}$ cells (synoviocytes or chondrocytes) was monitored in $2 \mathrm{ml}$ of airsaturated HBSS-glucose, in the presence of $50 \mathrm{mM}$ POBN and $2 \%$ $\mathrm{EtOH}(\mathrm{v} / \mathrm{v})$, with a Clark electrode, at $37^{\circ} \mathrm{C}$. The kinetics of $\mathrm{O}_{2}$ consumption was recorded with an oxygraph (Oroboros oxygraph, Paar Physica, Austria). The measurement started just after transferring the mixture in the respiration chamber (test chamber) and closing it. As control assays, $10^{7}$ cells were put in the same mixture in the second chamber of the oxymeter (control chamber), and their normal respiration rate was monitored without closing the chamber. The $A / R$ assays were performed as previously described [5]. The synoviocytes (cell line and primary equine cells) reached anoxia after complete consumption of the $\mathrm{O}_{2}$ in the medium, while for chondrocytes, the anoxia sequence was reached by bubbling the medium with $\mathrm{N}_{2}$. Anoxia was maintained during $20 \mathrm{~min}$, and followed by opening of the test chamber and re-oxygenation performed by exposure of the stirred medium to air until $\mathrm{O}_{2}$ saturation. Afterwards, the respiration chamber was again closed, the respiration rate was monitored and a new cycle of $A / R$ was performed. Three cycles of $A / R$ were performed. For equine articular chondrocytes, each period of anoxia was reached by a new bubbling with nitrogen. At the end of the third anoxia period, the samples were subjected to EPR measurements (see below), and the cellular viability was determined by trypan blue exclusion. Oxymetry assays were done in triplicate for each cell line. The slopes of $\mathrm{O}_{2}$ consumption were calculated with the Orobos oxygraph included software. 
EPR spin trapping experiments. After the third sequence of anoxia, the cell suspension was transferred into the quartz flat cell and put into the cavity of the EPR spectrometer. The presence of free radicals was evaluated by following the production of POBN/ethoxy radical adducts. All measurements were carried out at room temperature with a Bruker spectrometer (Bruker, Karlsruhe, Germany), operating at X-band frequency $(9.75 \mathrm{GHz})$ and at a microwave power of $20 \mathrm{~mW}$. The instrumental settings were the following: $100 \mathrm{kHz}$ modulation frequency, $1.012 \mathrm{G}$ modulation amplitude, $3480 \mathrm{G}$ magnetic field centre, and receiver gain was $2 \times 10^{4}$. The sweep width was $100 \mathrm{G}$ and the total number of scans was 6 or more. The hyperfine splitting constants were measured from the experimental spectra by means of a Bruker Win-Simfonia program running under Microsoft Windows. The assays were repeated three times for each cell line.

\section{Results}

\section{Cell isolation and culture}

By enzymatic digestion from cartilage and synovial membranes, we isolated chondrocytes and synoviocytes with a viability $\geqslant 95 \%$. The chondrocytes were cultured for $48 \mathrm{~h}$ before the oxymetry and A/R assay: during this period, they maintained their phenotype, and their number and viability remained unchanged. Before oxymetry, the synoviocytes were cultured until confluence; after trypsination, their viability was $\geqslant 95 \%$.

\section{Respiration rate of joint cells and effects of anoxia}

Both, the rabbit and the primary equine synoviocytes presented the same respiratory rate, as shown in Fig. 1. We observed that $10^{7}$ synoviocytes completely consumed $\mathrm{O}_{2}$ within $20 \mathrm{~min}$, with a respiration slope around $11 \mu \mathrm{mol} \mathrm{O}_{2} / \mathrm{min}$ as presented in the typical example of Fig. 1 (curve 1). The A/R cycles slowered the respiration rate (Fig. 1, curves 2-4): the first anoxia period de-

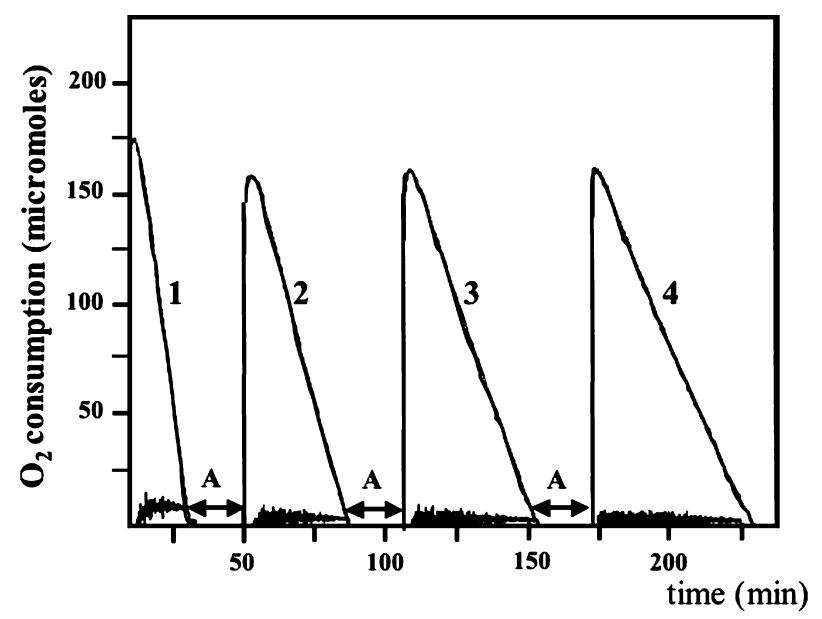

Fig. 1. Oxymetry of $10^{7}$ synoviocytes (HIG cell line) and effects of anoxia/re-oxygenation cycles. A indicates anoxia and the two-headed arrow the period of anoxia. Four slopes $(1-4)$ of $\mathrm{O}_{2}$ consumption were calculated: $11.0,5.5,4.0$, and $3.2 \mu \mathrm{mol} \mathrm{O}_{2} / \mathrm{min}$ respectively.

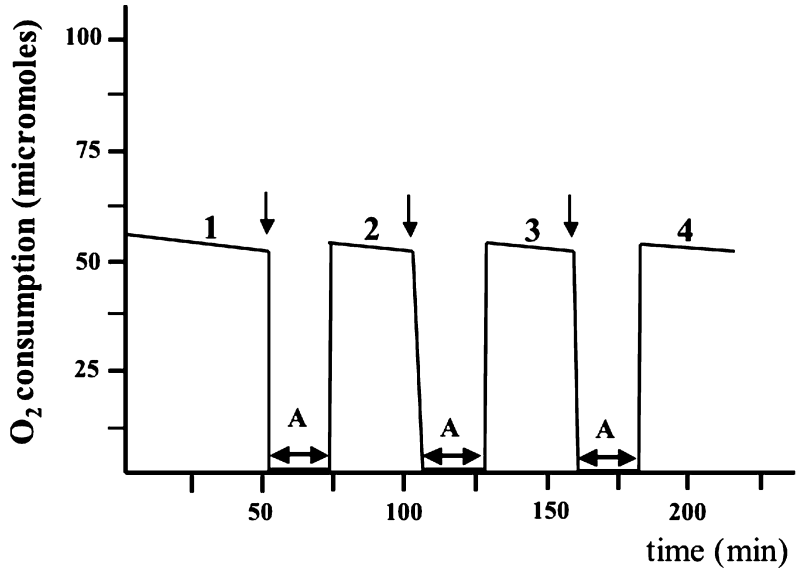

Fig. 2. Oxymetry of $10^{7}$ equine chondrocytes and effects of anoxia/reoxygenation cycles. A indicates anoxia and the two-headed arrow the period of anoxia. Arrow: $\mathrm{N}_{2}$ bubbling (necessary to reach anoxia).

creased the respiration slope to $5.55 \mu \mathrm{mol} \mathrm{O}_{2} / \mathrm{min}$ ( $50 \%$ decrease), and the decrease continued after the second and third anoxia periods but less accentuated, with respiration slopes of 4.0 and $3.22 \mu \mathrm{mol} \mathrm{O}_{2} / \mathrm{min}$, respectively. After the last period of anoxia, the shape of the curve changed (loss of linearity) indicating mitochondrial damage. Viability of the cells at the end of the experiment was $\geqslant 75 \%$. The respiration rate of $10^{7}$ equine articular chondrocytes was linear but the consumption of $\mathrm{O}_{2}$ was very weak $\left(0.14 \mu \mathrm{mol} \mathrm{O}_{2} / \mathrm{min}\right)$, so that the chondrocytes never reached anoxia spontaneously (Fig. 2): a bubbling with $\mathrm{N}_{2}$ was needed. The effects of repeated cycles of $A / R$ on their respiration rate were negligible without clear sign of slope change and thus no mitochondrial damage. The chondrocyte viability after the experiment was superior to $90 \%$.

\section{Free radical release observed by EPR: spin trapping studies}

EPR studies were performed with POBN with and without addition of EtOH. Normoxic control cells $\left(10^{7}\right.$ equine articular chondrocytes, HIG-82 rabbit synoviocytes or primary equine synoviocytes) in $2 \mathrm{ml} \mathrm{HBSS}$ $\mathrm{G}$, supplemented with $\mathrm{POBN}$ or $\mathrm{POBN} / \mathrm{EtOH}$ mixture did not show free radical signals. After three cycles of $\mathrm{A} / \mathrm{R}$, no free radical formation was observed in equine articular chondrocytes, but on the contrary, the EPR spectra of both types of synoviocytes, rabbit HIG-82 and primary equine synoviocytes, evidenced the production of free radicals (Figs. 3 and 4) and showed six-line EPR spectra characteristic of $\mathrm{POBN} / \cdot \mathrm{CH}(\mathrm{OH}) \mathrm{CH}_{3}$ adducts with the following coupling constants: $a_{\mathrm{N}}=15.7 \mathrm{G}$ and $a_{\mathrm{H}}=2.7 \mathrm{G}$ (Figs. $3 \mathrm{~B}$ and 4B). The EPR signal was more intense for primary equine synoviocytes (Fig. 4B). In contrast, after A/R cycles without the addition of ethanol, synoviocytes showed only 

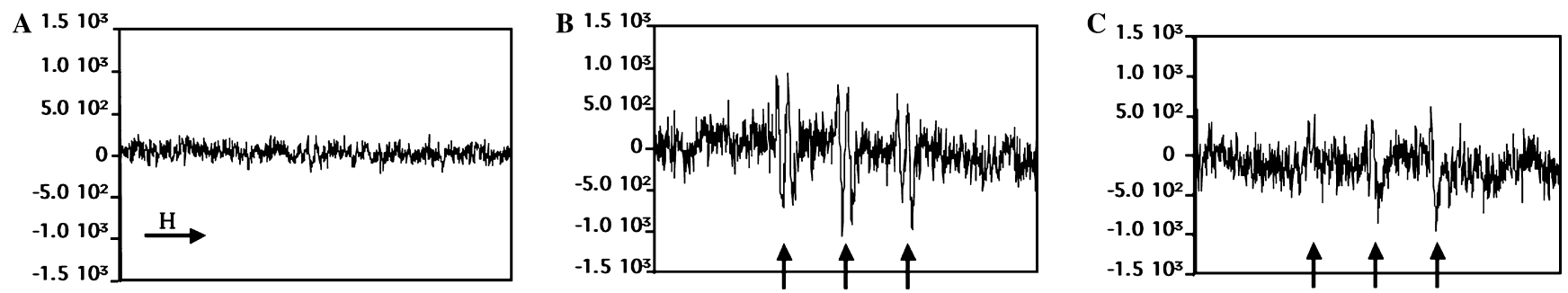

Fig. 3. EPR signal of $10^{7}$ rabbit synoviocytes obtained at the end of three anoxia/re-oxygenation cycles. Arrows indicate the signal lines. (A) Control (cells in normoxia), (B) POBN/ethoxy adduct, and (C) lipid radical production (POBN/L adduct).
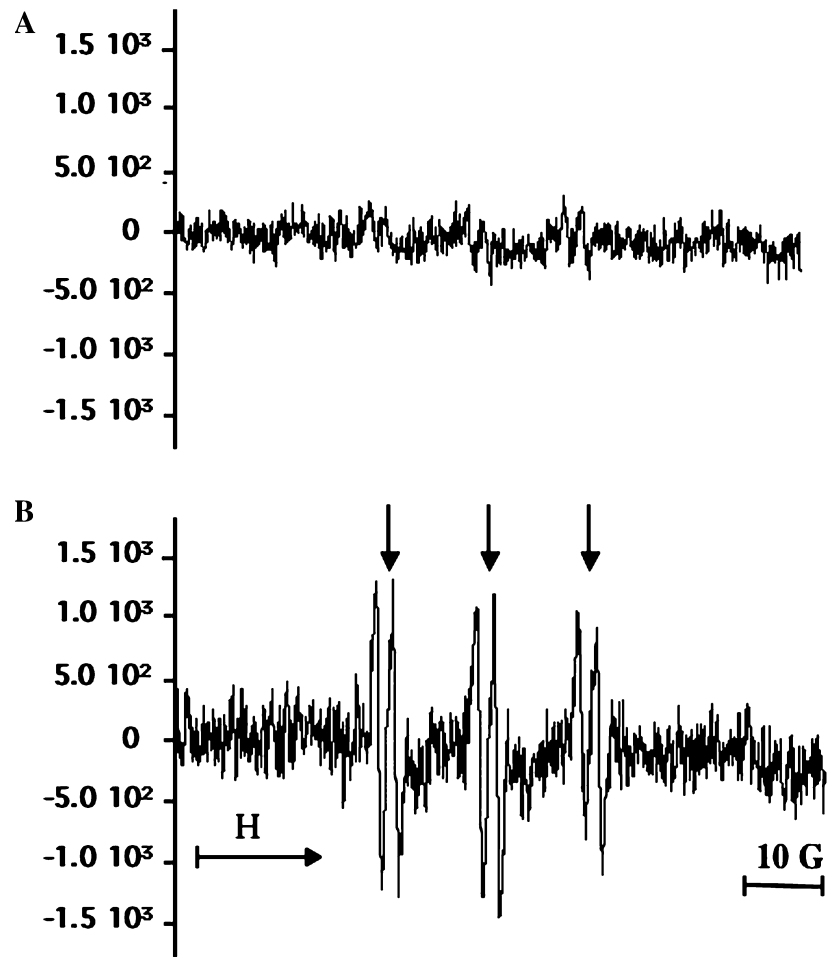

Fig. 4. EPR signal of $10^{7}$ primary equine synoviocytes obtained at the end of three anoxia/re-oxygenation cycles. Arrows indicate the signal lines. (A) Control (cells in normoxia) and (B) POBN/ethoxy adduct.

three-line EPR spectra (POBN/lipid adduct, $\left.a_{\mathrm{N}}=15.2 \mathrm{G}\right)$, suggesting carbon-centred radicals derived from lipid peroxidation (Fig. 3C).

\section{Discussion}

The oxymetric assays of synoviocytes in suspension indicated that the respiratory function of the cells was altered by repetitive cycles of $A / R$, and by EPR spin trapping methodology we found that free radicals were produced. Indeed after each cycle of $\mathrm{A} / \mathrm{R}$, the synoviocytes needed more time to consume the $\mathrm{O}_{2}$ of the medium before they achieved again anoxia. This effect can partially be attributed to a reduced viability, but after the last anoxia period, we also observed a parabolic shape in the oxymetric curves of the synoviocytes, indi- cating a disturbed mitochondrial chain activity. In our study, exogenous compounds known to stimulate cells were not added. The production of free radicals by synoviocytes was the result of a stimulation by cycles of $A / R$, an observation that has never been reported previously. The synoviocytes build or live at the border between joint cavity and joint capsule. They are exposed to $>12 \% \mathrm{O}_{2}$ saturation of the arterial blood whereas the chondrocytes live under hypoxic conditions (about 7\% $\mathrm{O}_{2}$ in the synovial liquid) [3]. These life conditions suggest that synoviocytes are more susceptible to $\mathrm{A} / \mathrm{R}$ than articular chondrocytes. Our oxymetry and EPR studies confirm this hypothesis, demonstrating a sensibility towards a lack of $\mathrm{O}_{2}$ and an oxidant activity of synoviocytes at least related to ROS production. EPR spectra of POBN/ethoxy adducts were observed during $A / R$ of isolated liver mitochondria and were attributed to the reaction of hydroxyl radicals, originating from superoxide anion, with the POBN/EtOH couple [6]. POBN can cross the mitochondrial membranes and reach the matrix compartment. The EPR signals that we reported here were similar to those obtained with isolated mitochondria, and suggested a mitochondrial origin: the observed EPR spectra of POBN/ethoxy adducts can be attributed to the reaction of superoxide anion by-product with ethanol in the presence of the spin trap agent [7]. Indeed, mitochondria are reported to produce superoxide anion and other ROS in normal as well as in pathological conditions of A/R [7-9]. The superoxide anion that is produced on the matrix side of the mitochondrial membrane can cause cell damage (e.g., lipid peroxidation) by reacting with metal iron complexes within the enzymatic domain. Superoxide anion was also described as able to attack the aconitase, releasing the labile iron of the cluster $[4 \mathrm{Fe}-4 \mathrm{~S}]^{2+}$ and forming $\mathrm{Fe}^{2+}[10]$. Superoxide anion also produces hydrogen peroxide $\left(\mathrm{H}_{2} \mathrm{O}_{2}\right)$ by subsequent dismutation, and both species, in the presence of $\mathrm{Fe}^{2+}$, may form the highly reactive species hydroxyl radicals which are known to cause cell damage especially by lipid peroxidation.

Superoxide anion can also react with nitric oxide (NO), of which the production is recognised in mitochondria and increases with increased $\mathrm{Ca}^{2+}$ concentrations, such as during anoxia $[9,11]$. From this reaction, 
peroxynitrite can be formed, from which new radical species are generated, such as hydroxyl radicals, favouring the peroxidation of membrane phospholipids and generating lipidic radical species.

With 4-POBN, we found spin adducts indicating the presence of other radical species with a longer life period. These radical species could originate from mitochondrial lipid peroxidation, maybe by in situ production of hydroxyl radical or other free radical species. Of course, we cannot exclude a cytosol origin of superoxide anion and derived species, by the anoxia-activated xanthine oxidase, but the simultaneous demonstration of an altered respiratory function suggested that the mitochondrial respiratory chain was damaged and so mainly responsible for the production of free radicals that could be primarily superoxide anions.

However, our study does not permit to say at which moment accurately the formation of free radical takes place. Further investigations are necessary to identify the sequence of radical production and to identify the nature of these radical species. At least, we can suspect the onset of free radical production during anoxia, increasing at re-oxygenation as it has been demonstrated for other cell types [5]. For chondrocytes, after A/R we did not observe change in the respiration rate or free radical production. Their respiration rate was very low, maybe explaining the absence of free radical at the mitochondrial level.

Tiku et al. [12] showed the production of superoxide and hydrogen peroxide by chondrocytes, but after stimulation by phorbol 12-myristate 13-acetate in the presence of ferrous iron. They also found a hydroxyl formation by unstimulated rabbit and human cartilage in the presence of ferrous iron. Their working conditions were comparable to inflammation conditions, which are considered as accompanied by reactive oxygen species production [13]. Our working conditions were different since we used $\mathrm{A} / \mathrm{R}$ without another stimulator. However, as we observed that synoviocytes formed ROS under A/R conditions, we cannot exclude that, in vivo, the production of reactive oxygen species by synoviocytes could damage iron binding proteins transferrin and ferritin and contribute to stimulate chondrocyte to produce ROS, in the presence of released iron.

\section{Conclusions}

The results demonstrated that $A / R$ of primary equine and immortalised rabbit synoviocytes led to respiratory dysfunction and to the production of free radicals. The free radicals seemed to originate, at least partially, from damaged mitochondria, but this hypothesis needs further investigation. On the contrary, primary equine articular chondrocytes did not show altered respiration patterns and formation of free radicals when exposed to anoxia. These observations indicate an important role of synoviocytes in the onset of osteoarthritis and suggest that chondrocytes could be, in a first time, the victims of free radicals built by synoviocytes, before they start their own inflammatory response.

\section{Acknowledgments}

This study has been established with the support of the "Ministère de l'Agriculture et de la Ruralité de la Région Wallonne" as a part of a project leaded by the "Centre Européen du cheval de Mont le Soie."

\section{References}

[1] C.W. McIlwraith, General pathophysiology of the joint and response to injury, in: C.W. McIlwraith, G.W. Wayne (Eds.), Joint Disease in the Horse, W.B. Saunders, Philadelphia, 1996, p. 43, Chapter 3.

[2] R.E. Allen, D.R. Blake, N.B. Nazhat, P. Jones, Superoxide radical generation by inflamed human synovium after hypoxia, Lancet 2 (1989) 282-283.

[3] M.J. Grimshaw, R.M. Mason, Bovine articular chondrocyte function in vitro depends upon oxygen tension, Osteoarthritis Cartilage 8 (2000) 386-392.

[4] N. Schneider, J.P. Lejeune, C. Deby, G.P. Deby-Dupont, D. Serteyn, Viability of equine articular chondrocytes in alginate beads exposed to different oxygen tensions, Vet. J. 168 (2004) 167173.

[5] A. Mouithys-Mickalad, M. Mathy-Hartert, G. Du, F. Sluse, C. Deby, M. Lamy, et al., Oxygen consumption and electron spin resonance studies of free radical production by alveolar cells exposed to anoxia: inhibiting effects of the antibiotic ceftazidime, Redox. Report 7 (2002) 85-94.

[6] G. Du, K. Willet, A. Mouithys-Mickalad, C. Sluse-Goffart, M.T. Droy-Lefaix, F. Sluse, EGb 761 protects liver mitochondria against injury induced by in vitro anoxia/re-oxygenation, Free Radic. Biol. Med. 27 (1999) 596-604.

[7] G. Du, A. Mouithys-Mickalad, F. Sluse, Generation of superoxide anion by mitochondria and impairment of their functions during anoxia and re-oxygenation in vitro, Free Radic. Biol. Med. 25 (1998) 1066-1074.

[8] G. Loschen, L. Flohe, B. Chance, Respiratory chain linked $\mathrm{H}_{2} \mathrm{O}_{2}$ production in pigeon heart mitochondria, FEBS Lett. 18 (1971) 261-264.

[9] A.Y. Andreyev, Y.E. Kushnareva, A.A. Starkov, Mitochondrial metabolism of reactive oxygen species, Biochemistry (Moscow) 70 (2005) 200-214.

[10] J. Vasquez-Vivar, B. Kalyanarama, M.C. Kennedy, Mitochondrial aconitase is a source of hydroxyl radical. An electron spin resonance investigation, J. Biol. Chem. 275 (2000) 14064-14069.

[11] P. Ghafourifar, E. Cadenas, Mitochondrial nitric oxide synthase, Trends Pharmacol. Sci. 26 (2005) 190-195.

[12] M.L. Tiku, Y.P. Yan, K.Y. Chen, Hydroxyl radical formation in chondrocytes and cartilage as detected by electron paramagnetic resonance spectroscopy using spin trapping reagents, Free Radic. Res. 29 (1998) 177-187.

[13] Y. Kawai, E. Kubota, E. Okabe, Reactive oxygen species participation in experimentally induced arthritis of the temporomandibular joint in rats, J. Dent. Res. 79 (2000) 1489-1495. 